\title{
Kratom-Pharmacology, Clinical Implications, and Outlook: A Comprehensive Review
}

\author{
Steven C. Eastlack · Elyse M. Cornett · Alan D. Kaye
}

Received: November 25, 2019 / Published online: January 28, 2020

(c) The Author(s) 2020

\begin{abstract}
Kratom, or Mitragyna, is a tropical plant indigenous to Southeast Asia, with unique pharmacological properties. It is commonly consumed by preparing the leaves into decoction or tea, or by grinding them into a powder. Recent evidence has revealed that kratom has physiological effects similar to opioids, including pain relief and euphoria, as well as stimulant properties, which together raise potential concern for dependence and addiction. Moreover, growing evidence suggests that the
\end{abstract}

Enhanced Digital Features To view enhanced digital features for this article go to https://doi.org/10.6084/ m9.figshare.11567916.

S. C. Eastlack

LSU Health Sciences Center School of Medicine, 1901 Perdido Street, New Orleans, LA 70112, USA

E. M. Cornett ( $\square)$

Department of Anesthesiology, LSU Health

Shreveport, 1501 Kings Highway, Shreveport, LA

71103, USA

e-mail: ecorne@lsuhsc.edu

A. D. Kaye

Department of Anesthesiology, Louisiana State University School of Medicine, 1501 Kings Hwy, Shreveport, LA 71103, USA prevalence of kratom use is increasing in many parts of the world, raising important considerations for healthcare providers. This manuscript will discuss the most current epidemiology, pharmacology, toxicity, and management related to kratom, while seeking to provide a contemporary perspective on the issue and its role in the greater context of the opioid epidemic.

Keywords: Drug abuse; Drug addiction; Kratom; Mitragynine; Opioid; Stimulant
A. D. Kaye

Department of Pharmacology, Toxicology, and Neurosciences, Louisiana State University School of Medicine, 1501 Kings Hwy, Shreveport, LA 71103, USA

A. D. Kaye

Tulane School of Medicine, New Orleans, LA 70112, USA 


\section{Key Summary Points}

Kratom (Mitragyna speciosa) is a botanical supplement with unique psychoactive properties.

The prevalence of kratom use appears to be increasing in Europe and North America, raising concerns for its possible development into a significant public health threat.

The body of scientific literature concerning kratom is expanding, but has not yet sufficiently characterized the nature and extent of the potential risks posed by kratom.

There is an increasing need for healthcare providers to be familiar with kratom and the management of patients who abuse it.

\section{INTRODUCTION}

Mitragyna speciose (Korth) is a tree-like herb consumed for its distinctive psychotropic properties [1]. Commonly known as "kratom"a term referring to both the plant itself and the botanical products derived from its leaves-the $M$. speciosa tree is a tropical evergreen indigenous to the southeastern Asia-Pacific region, sharing close phylogeny with the coffee plant in the Rubiaceae family [2]. The consumption of kratom has been commonplace within this region for centuries, but has also recently gained popularity in the West $[3,4]$.

Kratom is primarily sought out for its stimulant and opioid-like properties, and may be used either for its perceived therapeutic effects or as a recreational drug. In either case, there is considerable uncertainty regarding the safety of ingesting kratom products. Consequently, it is important that healthcare providers be familiar with the subject, as it represents a growing public health concern. There are multiple aspects for the medical field to consider in addressing the problem of kratom, including reducing interest and accessibility, optimizing

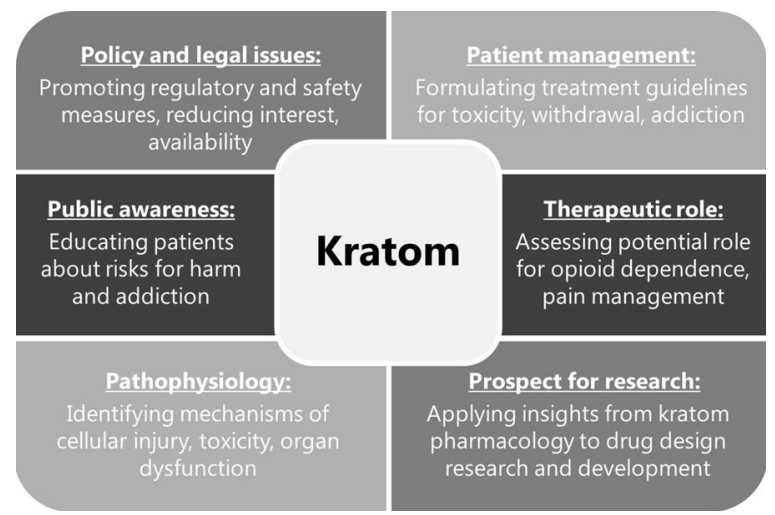

Fig. 1 Key considerations regarding kratom in the medical field. Figure is original and was produced by the authors for this particular publication

management of toxicity and dependence, and investigating its prospective use in research and therapeutics (Fig. 1).

The purpose of this review is to provide an in-depth discussion of these points, framing them within the greater context of the opioid crisis at large. Specifically, the article seeks to address the current epidemiology, pharmacology, and toxicity associated with kratom. In addition, we provide a synopsis on the clinical management of kratom in order to assist caretakers as they address patients suffering from overdose, addiction, and withdrawal related to the drug. To achieve these objectives, we have conducted an extensive and detailed literature review of the subject, incorporating both preclinical studies and clinical case reports in order to provide a fuller perspective on the matter.

This article is based on previously conducted studies and does not contain any studies with human participants or animals performed by any of the authors.

\section{KRATOM: BACKGROUND, PREVALENCE, AND LEGAL STATUS}

Kratom use has been customary in countries such as Thailand, Malaysia, and Myanmar for several hundred years [5]. Depending on the specific region, kratom is alternatively known as ketum, biak-biak, ithang, or thom [6]. Although raw leaves can be chewed or smoked for the 
effects, more frequently the leaves are boiled in water to produce decoctions or teas, which contain multiple biologically active phytochemicals, accounting for its psychoactive properties $[3,7]$. In addition to these more traditional methods of preparation, the leaves may be dried and processed into powders, capsules, and extracts, especially in western countries [8].

Historically, kratom has been used in traditional folk remedies for treating a range of ailments, for example, to mitigate symptoms of opiate addiction and withdrawal, or for weaning off dependence $[9,10]$. It is also frequently used to relieve pain, produce euphoria, and stave off fatigue, especially among laborers in rural areas [11]. Its potential for dependence and addiction has long been apparent, and led to its categorization as a banned substance in both Malaysia and Thailand in the mid-twentieth century (of note, the Thai National Assembly has recently made it legal for medical purposes) $[12,13]$. Nevertheless, the illicit use of kratom remains common; for instance, a survey conducted in Thailand in 2011 estimated the nationwide prevalence (lifetime) to be $2.9 \%$, with nearly half of those admitting to daily kratom use, making it among the most commonly used illicit substance in the country [14].

In recent years, commercial preparations of kratom have become increasingly available in regions far beyond its local origins. Large-scale epidemiological studies evaluating the prevalence of kratom use are scarce, but available evidence indicates that its prevalence is on the rise in the United States [15], Europe [16], and developed eastern countries such as Japan [17]. In the USA, over 1800 total calls related to kratom ingestion were received by US poison centers in the 7-year interval from 2011 through 2017, with nearly two-thirds of these occurring in the last 2 years of the period, signifying the rapid rise in the use of the substance [18]. Moreover, a recent synopsis on kratom estimated the number of users in the USA to be in the range of 3-5 million based on membership numbers obtained from the American Kratom Association [19]. If accurate, this would correspond to approximately $0.9-1.5 \%$ of the US population reportedly using kratom. This trend is also reflected in the expanding scientific literature, where the number of case reports describing kratom intoxication continue to accumulate [20-23].

Particularly in the West, kratom is often used as a recreational drug, where it is perceived as a safe, "legal high" [12]. This reputation led to the proposed categorization of kratom as a Schedule I drug by the US Drug Enforcement Administration (DEA) in 2016, but it garnered little interest among policymakers. Thus, a key contributor to the problem is that kratom remains unrecognized as a controlled substance by the DEA and is therefore not subject to regulation by the US Controlled Substances Act [24]. Although it is currently listed on the DEA's Drugs of Concern registry, this is mostly a symbolic measure and does little to prevent its sale. However, as of 2019, six states legislatures (Alabama, Arkansas, Indiana, Wisconsin, Rhode Island, and Vermont) have successfully passed statutes criminalizing kratom possession [25]. In the rest of the USA, it remains legal and is easily obtained in stores or through numerous online retailers. Its sale is permitted throughout Europe as well, with the exception of Poland, Ireland, and Romania, as well as most of the Nordic and Baltic states [26].

To be sure, its unscheduled status and widespread availability have contributed to the expansion of kratom within Western markets [27]. However, in the USA, the more fundamental issue underlying the growing demand for kratom is the current opioid abuse epidemic [28]. As prescribers are pressured to cut back on supplying opioid medications, patients with opioid dependence often resort to alternatives like kratom to support their habit as traditional opioids become scarce [29]. Kratom is also sought out by those who wish to self-medicate for health conditions such as chronic pain or opioid withdrawal/dependence, and it has been heralded as a legal, inexpensive alternative to opioid replacement regimens [30]. The efficacy of kratom for such purposes remains highly questionable, and more research is needed to establish a conclusive answer. 


\section{PHARMACOLOGY OF KRATOM AND PROSPECTS IN THERAPEUTICS AND RESEARCH}

Kratom does not denote a single, specific compound, but rather a cocktail of the psychoactive alkaloids occurring naturally in the plant. More than 40 of these compounds have been identified to date, although only four are known to be pharmacologically active: mitragynine, 7-hydroxymitragynine (7-OH- mitragynine), speciociliatine, and corynantheidine [31]. The most prevalent is mitragynine, which accounts for approximately $2 \%$ of kratom preparations by mass, but up to $66 \%$ of the total alkaloid content [32]. Its highly active oxidized metabolite, 7-OH-mitragynine, is present in far lower quantities, generally under $0.02 \%$ [33]. Other indole alkaloids present in significant concentrations include speciogynine, paynantheine, and mitraphylline [34]. Like the remaining trace alkaloids, these compounds are not known to be pharmacologically active; however, it is possible they may contribute synergistically to the overall effect of kratom in an unknown manner. Given the diversity of alkaloids present in kratom extracts and the unique potential pharmacodynamic properties of each, the net physiological effect of the substance is complex, intermixing stimulant and opiate-like properties in a dose-dependent manner (primarily stimulant-like at low amounts, with opioid effects predominating at higher doses) $[35,36]$.

Both mitragynine and 7-OH-mitragynine target opioid receptors, albeit with significant differences in binding affinity [37]. In fact, while the affinity of mitragynine for opioid receptors is less than that of morphine, 7-OHmitragynine is far more potent than either, approximately 46 times that of mitragynine and 13 times that of morphine [38, 39]. Despite considerable investigation, the precise manner in which kratom alkaloids act at each of the receptors remains disputed. For example, Takayama and colleagues have produced a sizeable body of work on the subject, indicating that both mitragynine and 7-OH-mitragynine behave as agonists, with mitragynine acting primarily on $\mu$ - and $\delta$-receptors and 7-OH-mitragynine more selective for $\mu$ - and $\kappa$-receptors [39-41]. However, competing evidence suggests a different model; rather than acting as simple agonists, mitragynine and 7-OH-mitragynine appear to demonstrate variable effects depending on the receptor. Specifically, the data show that both mitragynine and 7-OH-mitragynine are mixed opioid receptor agonists/antagonists, behaving as partial agonists at $\mu$-receptors and competitive antagonists at $\delta$-receptors, with negligible effects on $\kappa$-receptors [42].

Importantly, the indole alkaloids in kratom are structurally and pharmacodynamically distinct from their opioid counterparts, producing partially overlapping but nonidentical effects. Accordingly, these compounds have been called atypical opioids to distinguish them from morphine, semisynthetic opioids, and endogenous ligands [43]. Like the opioids, binding of the indole alkaloids to opioid receptors initiates G-protein-coupled receptor (GPCR) signaling; however, unlike traditional opioids, the activation of GPCRs by indole alkaloids does not initiate the $\beta$-arrestin pathway [44]. This phenomenon, known as biased agonism or ligand-directed signaling, enables a single receptor to mediate multiple different intracellular effects by selectively disengaging the various signaling cascades coupled to the receptor [45]. Interestingly, $\beta$-arrestin recruitment is responsible for most of the symptomology associated with opioid use (e.g., respiratory depression, sedation, constipation) $[46,47]$. Thus, the selective inactivation of $\beta$-arrestin represents a desirable feature for an opioid, and suggests that mitragynine might be a useful template for designing novel opioids with more tolerable side effect profiles.

In addition to its opioid-like analgesic effects, mitragynine appears to block pain signaling through other mechanisms as well, suggesting a multimodal role in regulating pain perception. For instance, mitragynine shares considerable structural homology with yohimbine, another indole alkaloid, which has wellknown adrenergic properties [37]. Like yohimbine, experimental evidence indicates that mitragynine activates $\alpha-2$ adrenergic postsynaptic receptors [48]. This is significant for 
mitragynine's analgesic effects, as $\alpha-2$ receptors are present in modulatory "descending" pain pathways [49]. The importance of these pathways has only recently become apparent, and represent a major advancement in the complex neurobiological understanding of pain [50]. A third anti-nociceptive mechanism has been proposed in light of evidence that mitragynine impairs neuronal pain transmission via blockade of $\mathrm{Ca}^{2+}$ channels [51]. Additionally, indirect analgesic properties have been attributed to mitragynine's putative anti-inflammatory effects, secondary to the inhibition of COX-2 and prostaglandin $\mathrm{E}_{2}$ mRNA expression $[52,53]$. In addition to these anti-nociceptive functions, mitragynine bears some affinity for receptors in the central nervous system, including the $5-\mathrm{HT}_{2 \mathrm{C}}$ and $5-\mathrm{HT}_{7}$ serotonin receptors, $\mathrm{D}_{2}$ dopamine receptors, and $\mathrm{A}_{2 \mathrm{~A}}$ adenosine receptors, but the physiological significance of these interactions is unclear [41].

The metabolism of kratom alkaloids is primarily hepatic, with several cytochrome P450 (CYP) isoforms involved, including CYP3A4, with lesser contributions from CYP2D6 and CYP2C9 [54]. It demonstrates linear pharmacokinetics and has a biphasic elimination pattern from the plasma when ingested orally, suggesting a two-compartment model of distribution [55]. The half-life of mitragynine has been reported to be as short as 3 hours, although some studies suggest it may be much longer [56, 57]. A major development in the understanding of kratom pharmacology has been the recognition that mitragynine is converted into 7-OH-mitragynine by hepatic metabolism in vivo [58-60]. Consequently, it has been postulated that 7-OH-mitragynine actually represents the active metabolite of mitragynine, accounting for most or all of the effects traditionally attributed to the mitragynine precursor. This hypothesis was first described by a trio of 2019 publications conducted by three separate groups [58-60]. These studies provided evidence that the activation of mitragynine occurs by CYP34A-mediated dehydrogenation-a process analogous to the activation of opiates such as codeine, which is converted into is active metabolite by CYP2D6. Although 7-OH-mitragynine is present in kratom extracts, it occurs at trace concentrations, leaving the authors to conclude that any ingested 7-OH-mitragynine is inconsequential relative to the endogenous generation of $7-\mathrm{OH}-$ mitragynine derived from mitragynine. As current work is limited to animal models, future studies will need to confirm the relevance of this discovery in human physiology.

\section{EFFECTS OF KRATOM ALKALOIDS IN PRECLINICAL STUDIES}

Concern for the potential adverse effects associated with kratom has led to numerous preclinical investigations on the subject, such as the risk for dependence and addiction posed by mitragynine and related alkaloids. For instance, both mice and rat models have demonstrated addiction potential and cognitive impairment particularly in the setting of chronic mitragynine ingestion [61-63]. Studies also have found that the development of addiction and toxicity is specifically dependent on 7-OH-mitragynine, with mitragynine posing a minor risk [61, 64]. Moreover, chronic use has been associated with enhanced punishment tolerance and rewardseeking behavior [65]. Despite these adverse properties, animal model studies have also identified possible benefits; for example, mitragynine appears to slow the development of opioid tolerance when co-administered with morphine in mice, an observation which raises interesting possibilities for clinical applications [66].

Kratom has also been implicated as a cause of organ dysfunction and toxicity [67]. Animal studies have indicated a risk for drug-drug interactions, namely through modulating hepatic P450 activity and drug metabolism [68, 69]. Mitragynine also appears to inhibit hepatic demethylases and transferases, as well as glucuronidation by UDP-glucuronosyltransferases (UGT) such as UGT2B7 and UGT1A1 [70-73]. This bears important implications for a possible interaction when kratom is co-administered with other drugs known to be UGT substrates (e.g., buprenorphine and ketamine, metabolized by UGT2B7) [73]. Such findings have been used as a potential explanation for cases of 
toxicity following co-ingestion of kratom with other medications, including a reported fatality secondary to toxicity from supratherapeutic levels of a prescribed antipsychotic concurrent with kratom ingestion [74]. The authors attribute this outcome to a drastic reduction in clearance of quetiapine (a CYP3A4 substrate) secondary to the acute suppression of hepatic metabolism by kratom.

Clearly, the basic science literature raises legitimate concerns regarding the potential for drug toxicity and behavioral risks following kratom ingestion. However, a major limitation of the preclinical literature is that many of the experiments were conducted using either chemically synthesized mitragynine or $7-\mathrm{OH}-$ mitragynine rather than actual kratom (although a few studies utilized kratom leaf methanolic extracts) [75-77]. Consequently, such evidence likely represents an oversimplified and incomplete portrayal of the possible effects attributable to actual kratom consumption. This fundamental distinction must be considered prior to drawing any conclusions about patient safety from preclinical investigations.

\section{POTENTIAL FOR ADDICTION AND TOXICITY}

As alluded to earlier, the historical record concerning kratom's potential for dependence and addiction in humans raises strong concerns about its safety $[41,62,78]$. However, in many cases the primary motivation among regular users may simply be as a means to prevent exhaustion, and improve energy or mood. In such cases, routine use may not constitute dependence or addiction per se, but rather merely the desire to improve productivity [9]. This is in alignment with "drug instrumentation" theories, in which a substance is utilized in a purposeful, goal-directed manner [79, 80]. Such theories may account for the low incidence of kratom use disorder and other side effects among traditional users in Southeast Asia [81-85]. Nevertheless, the successful instrumentation of kratom does not preclude the potential for prolonged drug use, which under certain circumstances can degenerate into outright addiction [78]. It has also been proposed that a significant amount of kratom use occurs as a substitute for more harmful substances (namely narcotics) in patients with existing substance abuse, in which case kratom use represents a sort of harm reduction rather than drug abuse [79, 86]. Yet, while there is convincing evidence that kratom has significantly less potential for dependence and overdose than traditional opioids, the use of kratom in place of established medical opioid replacement regimens has little basis in evidence [30, 87, 88].

Aside from its potential for abuse, kratom poses numerous others risks to patients, largely a consequence of its status as an unregulated supplement. Without regulatory oversight, there is little to ensure the authenticity, purity, quality, potency, and safety of commercially available kratom preparations [89]. Consequently, it is difficult to know for certain what is actually present within commercially available kratom preparations, and the concentration of mitragynine contained can vary considerably [90]. For instance, it has been reported that kratom products may be altered by artificially increasing levels of 7-OH-mitragynine to enhance potency [91]. In addition, multiple instances of deliberate adulteration of kratom have been documented, for instance, by adding synthetic substances such as phenylethylamine (PEA) or O-desmethyltramadol, both of which have resulted in patient deaths [92, 93]. Other risks include product contamination (intentional or otherwise). For example, laboratory and epidemiological evidence identified kratom as the source of a multi-state salmonella outbreak in 2018 [94, 95]. There have also been cases describing the sale of kratom products later found to contain harmful heavy metal contaminants [96]. As there is considerable disparity between reported kratom toxicities in the West and in Southeast Asia (where it is comparatively uncommon), it has been suggested that misinformation regarding the content and potency of kratom may be largely responsible for the apparent danger attributed to kratom use [36]. 


\section{CLINICAL PRESENTATIONS OF KRATOM ABUSE}

Seeking to gauge the spectrum of possible symptoms associated with kratom toxicity, a 2019 retrospective review of cases reported to the National Poison Data System and New York City Office of the Chief Medical Examiner identified a wide variety of presenting symptoms, with agitation being the most common at $18.6 \%$, followed by tachycardia at $16.9 \%$, drowsiness at $13.6 \%$, and confusion at $8.1 \%$ [97]. Serious neurological sequelae included seizures in $6.1 \%$ of cases, and hallucinations in $4.8 \%$, with $2.3 \%$ progressing to coma. Toxicity occurred in a dose-dependent manner, particularly when doses of kratom powder exceeded 8 g. The study also determined kratom to be a contributing factor in at least four deaths. Consequently, the authors concluded that kratom supplements pose a public health risk and should not be presumed safe despite being legal for purchase.

Case studies reveal that a wide range of organ systems are susceptible to kratom-mediated injury (Table 1). For example, instances of kidney injury [67], cardiotoxicity and arrhythmia [98, 99], thyroid injury and hypothyroidism [100] lung injury/acute respiratory distress syndrome (ARDS) [101, 102], neonatal abstinence syndrome, [103-107] and hepatic injury [23, 108-116] have all been linked to kratom.
Hepatic injury is an especially common presentation, and often presents with a cholestatic hepatitis pattern similar to other drug-related injuries: transaminitis (usually with levels above 100 units/L) along with an elevated alkaline phosphatase ( $>200$ units/L) and total bilirubin $(>1.2 \mathrm{mg} / \mathrm{dL})$. A variety of neurological complications due to kratom toxicity have also been described, including acute brain injury and coma [21], along with the risk of seizures in both the acute and chronic setting [117, 118]. Long-term cognitive impairment may develop after long-term chronic users [81].

In certain severe cases, kratom toxicities have resulted in death. In fact, the incidence of kratom-related mortality appears to be rising, according to reporting by the Centers for Disease Control and Prevention (CDC), which linked kratom to 152 deaths between 2016 and 2017 [96]. Importantly, the existence of polysubstance abuse is a key risk factor predisposing patients to toxicity and death and has been estimated to occur in $87 \%$ of cases [119]. This has led to the belief that death resulting solely from ingestion of kratom is exceedingly rare, even impossible. However, in a 2019 article assessing kratom-related mortality in the state of Colorado, the authors reported that at least 4 of the 15 total deaths between 1999 and 2017 were attributable exclusively to mitragynine toxicity, a result which the authors confirmed using an extensive toxicological and

Table 1 Spectrum of organ system involvement and corresponding injuries associated with kratom use as identified in the case study literature

\begin{tabular}{lll}
\hline Organ system & Presentation signs and conditions & References \\
\hline Hepatic & Acute liver failure, hepatitis, transaminitis, intrahepatic cholestasis, hepatomegaly & {$[23,108-116,131]$} \\
Endocrine & Hypothyroidism, hypogonadism & {$[26,100]$} \\
Renal & Acute kidney injury & {$[67]$} \\
Cardiac & Cardiotoxicity, arrhythmia & {$[98,99]$} \\
Pulmonary & Acute lung injury, ARDS & {$[101,102]$} \\
Obstetric & Neonatal abstinence syndrome & {$[103-107]$} \\
Neurological & Acute brain injury, seizure, coma, cognitive impairment & {$[21,81,117,118]$} \\
\hline
\end{tabular}

$A R D S$ acute respiratory distress syndrome

Table is original and was produced by the authors for this particular publication 
biochemical workup [120]. Nevertheless, it remains probable that most kratom-related deaths are the result of kratom toxicity superimposed upon the effects of some other noxiousness factor, such as adulterants or contaminants within the kratom product itself, or in conjunction with the ingestion of another illicit substance.

\section{CONSIDERATIONS FOR TREATMENT AND MANAGEMENT}

The management of patients abusing kratom can be divided according to three objectives, each addressing a different scenario: (1) stabilization and prevention of organ injury in the setting of intoxication/overdose; (2) alleviation of the symptoms during acute withdrawal; and (3) long-term maintenance of sobriety for behavioral addiction. While there are no published guidelines specifically indicated for kratom, it is reasonable to begin management in a manner similar to that employed for patients presenting with opioid abuse. However, kratom may pose greater potential risk for drug toxicity and organ injury than might be expected with opioids.

In cases of kratom overdose, management is largely supportive. While reversal agents are standard of care for opioid overdose, their efficacy in cases of kratom overdose has not yet been evaluated in clinical trials. However, anecdotal evidence from various case studies supports its use, and it is widely speculated to be beneficial [121, 122]. This has led several experts to recommend it $[123,124]$. Depending on the organ system(s) involved, certain additional interventions may also be warranted. Acute hepatitis can be managed with $\mathrm{N}$-acetylcysteine in a manner analogous to other cases of drug-induced hepatitis [125]. If seizures or neurological symptoms are present, appropriate management with anti-epileptics is warranted [21]. Kidney injury, cardiovascular events, or other emergency presentation should be similarly addressed with the appropriate measures. The symptomology of kratom overdose can mimic the opioid toxidrome, particularly when patients consume more than $15 \mathrm{~g}$ of kratom [125]. Given the absence of any effective therapies, primary prevention is the ideal method for lowering a patient's long-term risk for morbidity and mortality. However, screening is dependent upon patient disclosure, as kratom is not detectable with any commercially available toxicology screens.

Patients presenting with symptoms of kratom withdrawal tend to exhibit a clinical picture similar to that seen in opioid withdrawal [126]. This includes somatic complaints such as nausea/vomiting, chills, diarrhea, sialorrhea/ rhinorrhea, body aches, restlessness, and irritability [78]. Physical exam findings include mydriasis, hypothermia, tremors, and diaphoresis. Additionally, a significant number of patients report psychiatric symptoms, most commonly nervousness, anxiety, and depression [33, 127]. Patients in acute withdrawal are managed conservatively, although there is some evidence to suggest that the combination of buprenorphine and naloxone can alleviate both the physical and mental symptoms associated with kratom withdrawal [128]. Additional evidence suggests positive results using high-dose clonidine or other $\alpha-2$ agonists in combination with hydroxyzine [129].

For patients with chronic kratom addiction and drug cravings, long-term pharmacological replacement therapy may be warranted. Kratom addiction often begins in the setting of patients suffering from opioid dependence, in part because it is perceived as a cheaper, more natural alternative to buprenorphine or methadone in those who wish to cease their abuse of narcotics. However, as previously stated, there is currently no reliable clinical evidence that kratom is an effective alternative for achieving this purpose [30, 88]. Consequently, such patients risk developing habitual kratom use as well, while leaving their underlying chronic addiction inadequately addressed. For motivated kratom-dependent patients actively seeking long-term control of drug cravings in the medical setting, treatment regimens are identical to those employed for traditional opioid dependence, given the lack of empirical treatment guidelines for kratom specifically. However, presumptive management using opioid- 
replacement therapy with methadone, buprenorphine, or buprenorphine-naloxone regimens have reportedly been effective $[128,130]$. Lastly, consideration should also be given to referral of patients for counseling or enrollment in 12-step addiction treatment programs.

\section{CONCLUSIONS}

Although not an epidemic in its own right, the current trends in kratom use are cause for steadily growing concern, and it is likely to become a significant public issue in the near future if it continues on its current trajectory. In seeking to address it, the problem must be understood within the greater context of the current epidemic of opioid abuse, as the desire to alleviate opioid withdrawal symptoms is a critical factor accounting for patients who seek out and abuse kratom. Because it is primarily a consequence of the opioid crisis, it will be difficult to adequately address this issue until the larger opioid problem is resolved. Even then, use of kratom will continue among non-addicts who wish to abuse it for recreational purposes. In this regard, taking actions to limit access may be warranted. But even in the event that kratom is scheduled as a controlled substance, it will likely remain available through clandestine dealings, just as many currently controlled illicit substances are. Given the likelihood of protracted demand for kratom use, health providers and medical educators should take efforts to improve awareness of this still relatively unknown drug.

In addition to promoting awareness among healthcare professionals, there is a great need for more extensive, high-quality studies to better understand the mechanism of its toxicity and to formulate specific and credible guidelines for the management of kratom ingestion. Patients should be made aware of the potential harm kratom poses, including predictable risks such as dependence and toxicity, and unpredictable risks related to product quality and contamination. However, the rising importance and interest in this issue presents new opportunities for research on kratom in the context of opioid pharmacology, and ultimately will support the development of new and improved analgesic agents.

\section{ACKNOWLEDGEMENTS}

Funding. No funding or sponsorship was received for this study or publication of this article.

Authorship. All named authors meet the International Committee of Medical Journal Editors (ICMJE) criteria for authorship for this article, take responsibility for the integrity of the work as a whole, and have given their approval for this version to be published.

Disclosures. Steven C. Eastlack and Elyse M. Cornett have nothing to disclose. Alan David Kaye is a member of the journal's Editorial Board.

Compliance with Ethics Guidelines. This article is based on previously conducted studies and does not contain any studies with human participants or animals performed by any of the authors.

Data Availability. Data sharing is not applicable for this article, as no data sets were generated or analyzed during the current study.

Open Access. This article is distributed under the terms of the Creative Commons Attribution-NonCommercial 4.0 International License (http://creativecommons.org/licenses/ by-nc/4.0/), which permits any noncommercial use, distribution, and reproduction in any medium, provided you give appropriate credit to the original author(s) and the source, provide a link to the Creative Commons license, and indicate if changes were made.

\section{REFERENCES}

1. Suwanlert S. A study of kratom eaters in Thailand. Bull Narc. 1975;27(3):21-7. 
2. Davis A. Rubiaceae of Thailand-a pictorial guide to indigenous and cultivated genera. Bot J Linn Soc. 2006;152(1):131-2.

3. Jansen KL, Prast CJ. Ethnopharmacology of kratom and the Mitragyna alkaloids. J Ethnopharmacol. 1988;23(1):115-9.

4. Henningfield JE, Fant RV, Wang DW. The abuse potential of kratom according the 8 factors of the controlled substances act: implications for regulation and research. Psychopharmacology. 2018;235(2):573-89.

5. Singh D, Narayanan S, Vicknasingam B, Corazza O, Santacroce R, Roman-Urrestarazu A. Changing trends in the use of kratom (Mitragyna speciosa) in Southeast Asia. Hum Psychopharmacol Clin Exp. 2017;32(3):e2582.

6. Adkins EJ, Boyer WE, McCurdy RC. Mitragyna speciosa, a psychoactive tree from Southeast Asia with opioid activity. Curr Top Med Chem. 2011;11(9): 1165-75.

7. Jansen KLR, Prast CJ. Psychoactive properties of mitragynine (Kratom). J Psychoactive Drugs. 1988;20(4):455-7.

8. Brown PN, Lund JA, Murch SJ. A botanical, phytochemical and ethnomedicinal review of the genus Mitragyna korth: implications for products sold as Kratom. J Ethnopharmacol. 2017;202:302-25.

9. Singh D, Narayanan S, Muller CP, Swogger MT, Chear NJY, Bin DE, et al. Motives for using Kratom (Mitragyna speciosa Korth.) among regular users in Malaysia. J Ethnopharmacol. 2019;233:34-40.

10. Vicknasingam B, Narayanan S, Beng GT, Mansor SM. The informal use of ketum (Mitragyna speciosa) for opioid withdrawal in the northern states of peninsular Malaysia and implications for drug substitution therapy. Int J Drug Policy. 2010;21(4): 283-8.

11. Assanangkornchai S, Muekthong A, Sam-angsri N, Pattanasattayawong U. The use of Mitragynine speciosa ("Krathom"), an addictive plant. Thailand. Subst Use Misuse. 2007;42(14):2145-57.

12. Cinosi E, Martinotti G, Simonato $P$, Singh D, Demetrovics Z, Roman-Urrestarazu A, et al. Following "the roots" of Kratom (Mitragyna speciosa): the Evolution of an enhancer from a traditional use to increase work and productivity in Southeast Asia to a recreational psychoactive drug in Western Countries. Biomed Res Int. 2015;2015:968786. https://doi.org/10.1155/2015/968786. https://www. ncbi.nlm.nih.gov/pubmed/26640804.
13. Ya K, Tangamornsuksan W, Scholfield CN, Methaneethorn J, Lohitnavy M. Pharmacokinetics of mitragynine, a major analgesic alkaloid in kratom (Mitragyna speciosa): a systematic review. Asian J Psychiatr. 2019;43:73-82.

14. Likhitsathian S, Jiraporncharoen W, Aramrattana A, Angkurawaranon C, Srisurapanont M, Thaikla K, et al. Polydrug use among kratom users: findings from the 2011 Thailand National Household Survey. J Subst Use. 2018;23(4):384-9.

15. Forrester MB. Kratom exposures reported to Texas poison centers. J Addict Dis. 2013;32(4):396-400.

16. Nizar H, Dargan PI, Wood DM. Using internet snapshot surveys to enhance our understanding of the availability of the novel psychoactive substance 4-methylaminorex and 4,4'-dimethylaminorex. J Med Toxicol. 2015;11(1):80-4.

17. Kikura-Hanajiri R, Uchiyama N, Goda Y. Survey of current trends in the abuse of psychotropic substances and plants in Japan. Leg Med. 2011;13(3): 109-15.

18. Post S, Spiller HA, Chounthirath T, Smith GA. Kratom exposures reported to United States poison control centers: 2011-2017. Clin Toxicol (Phila). 2019;57(10):847-54.

19. Grundmann O. Patterns of Kratom use and health impact in the US-Results from an online survey. Drug Alcohol Depend. 2017;176:63-70.

20. Matson M, Schenk N. Fatality of 33-year-old man involving kratom toxicity. J Forensic Scie. 2019;64: 1933-5.

21. Nelsen JL, Lapoint J, Hodgman MJ, Aldous KM. Seizure and coma following Kratom (Mitragynina speciosa Korth) exposure. J Med Toxicol. 2010;6(4): 424-6.

22. Kronstrand R, Roman M, Thelander G, Eriksson A. Unintentional fatal intoxications with mitragynine and $O$-desmethyltramadol from the herbal blend Krypton. J Anal Toxicol. 2011;35(4):242-7.

23. Kapp FG, Maurer HH, Auwarter V, Winkelmann M, Hermanns-Clausen M. Intrahepatic cholestasis following abuse of powdered kratom (Mitragyna speciosa). J Med Toxicol. 2011;7(3):227-31.

24. DEA. Drug Enforcement Administration, August 30, 2016. DEA announces intent to schedule kratom. 2016.

25. Dwyer K. Kratom Reserach Report. Connecticut general assembly office of legislative research. 2019. 
26. A Guide to Kratom Legality: Where Is Kratom Legal? Speciosa Guid. 2019;.

27. Veltri C, Grundmann O. Current perspectives on the impact of Kratom use. Subst Abuse Rehabil. 2019;10:23-31.

28. Whitehouse.gov. President Donald J. Trump is taking action on drug addiction and the opioid crisis. 2017.

29. FDA Statement. Statement from FDA Commissioner Scott Gottlieb, M.D. on FDA advisory about deadly risks associated with kratom. 2017.

30. Boyer EW, Babu KM, Macalino GE. Self-treatment of opioid withdrawal with a dietary supplement, Kratom. Am J Addict. 2007;16(5):352-6.

31. Takayama H. Chemistry and pharmacology of analgesic indole alkaloids from the rubiaceous plant, Mitragyna speciosa. Chem Pharm Bull (Tokyo). 2004;52(8):916-28.

32. Shellard EJ. The alkaloids of Mitragyna with special reference to those of Mitragyna speciosa. Korth. Bull Narc. 1974;26(2):41-55.

33. Kruegel AC, Grundmann O. The medicinal chemistry and neuropharmacology of kratom: a preliminary discussion of a promising medicinal plant and analysis of its potential for abuse. Neuropharmacology. 2018;134(Pt A):108-20.

34. Chittrakarn S, Penjamras P, Keawpradub N. Quantitative analysis of mitragynine, codeine, caffeine, chlorpheniramine and phenylephrine in a kratom (Mitragyna speciosa Korth.) cocktail using high-performance liquid chromatography. Forensic Sci Int. 2012;217(1-3):81-6.

35. Babu KM, McCurdy CR, Boyer EW. Opioid receptors and legal highs: salvia divinorum and Kratom. Clin Toxicol (Phila). 2008;46(2):146-52.

36. Singh D, Narayanan S, Vicknasingam B. Traditional and non-traditional uses of Mitragynine (Kratom): a survey of the literature. Brain Res Bull. 2016;126: $41-6$.

37. Prozialeck WC, Jivan JK, Andurkar SV. Pharmacology of kratom: an emerging botanical agent with stimulant, analgesic and opioid-like effects. J Am Osteopath Assoc. 2012;112(12):792-9.

38. Yamamoto LT, Horie S, Takayama H, Aimi N, Sakai $S$, Yano $S$, et al. Opioid receptor agonistic characteristics of mitragynine pseudoindoxyl in comparison with mitragynine derived from Thai medicinal plant Mitragyna speciosa. Gen Pharmacol Vasc Syst. 1999;33(1):73-81.
39. Matsumoto K, Horie S, Ishikawa $H$, Takayama $H$, Aimi N, Ponglux D, et al. Antinociceptive effect of 7-hydroxymitragynine in mice: discovery of an orally active opioid analgesic from the Thai medicinal herb Mitragyna speciosa. Life Sci. 2004;74(17): 2143-55.

40. Matsumoto K, Hatori Y, Murayama T, Tashima K, Wongseripipatana S, Misawa $\mathrm{K}$, et al. Involvement of mu-opioid receptors in antinociception and inhibition of gastrointestinal transit induced by 7-hydroxymitragynine, isolated from Thai herbal medicine Mitragyna speciosa. Eur J Pharmacol. 2006;549(1-3):63-70.

41. Matsumoto $\mathrm{K}$, Horie S, Takayama $\mathrm{H}$, Ishikawa $\mathrm{H}$, Aimi N, Ponglux D, et al. Antinociception, tolerance and withdrawal symptoms induced by 7-hydroxymitragynine, an alkaloid from the Thai medicinal herb Mitragyna speciosa. Life Sci. 2005;78(1):2-7.

42. Kruegel AC, Gassaway MM, Kapoor A, Varadi A, Majumdar S, Filizola M, et al. Synthetic and receptor signaling explorations of the mitragyna alkaloids: mitragynine as an atypical molecular framework for opioid receptor modulators. J Am Chem Soc. 2016;138(21):6754-64.

43. Raffa RB, Pergolizzi JV, Taylor R, Ossipov MH. Nature's first "atypical opioids": kratom and mitragynines. J Clin Pharm Ther. 2018;43(3):437-41.

44. Varadi A, Marrone GF, Palmer TC, Narayan A, Szabo MR, Le Rouzic V, et al. Mitragynine/corynantheidine pseudoindoxyls as opioid analgesics with mu agonism and delta antagonism, which do not recruit beta-arrestin-2. J Med Chem. 2016;59(18): 8381-97.

45. Wisler JW, Xiao K, Thomsen ARB, Lefkowitz RJ. Recent developments in biased agonism. Curr Opin Cell Biol. 2014;27:18-24.

46. Raehal KM, Bohn LM. The role of beta-arrestin2 in the severity of antinociceptive tolerance and physical dependence induced by different opioid pain therapeutics. Neuropharmacology. 2011;60(1): 58-65.

47. Bohn LM, Lefkowitz RJ, Caron MG. Differential mechanisms of morphine antinociceptive tolerance revealed in ßarrestin-2 knock-out mice. J Neurosci. 2002;22(23):10494-500.

48. Matsumoto K, Mizowaki M, Suchitra T, Murakami Y, Takayama H, Sakai S, et al. Central antinociceptive effects of mitragynine in mice: contribution of descending noradrenergic and serotonergic systems. Eur J Pharmacol. 1996;317(1):75-81. 
49. Giovannitti JAJ, Thoms SM, Crawford JJ. Alpha-2 adrenergic receptor agonists: a review of current clinical applications. Anesth Prog. 2015;62(1):31-9.

50. Ismail I, Wahab S, Sidi H, Das S, Lin LJ, Razali R. Kratom and future treatment for the opioid addiction and chronic pain: periculo beneficium? Curr Drug Targets. 2019;20(2):166-72.

51. Matsumoto K, Yamamoto LT, Watanabe K, Yano S, Shan J, Pang PKT, et al. Inhibitory effect of mitragynine, an analgesic alkaloid from Thai herbal medicine, on neurogenic contraction of the vas deferens. Life Sci. 2005;78(2):187-94.

52. Shaik Mossadeq WM, Sulaiman MR, Tengku Mohamad TA, Chiong HS, Zakaria ZA, Jabit ML, et al. Anti-inflammatory and antinociceptive effects of Mitragyna speciosa Korth methanolic extract. Med Princ Pract. 2009;18(5):378-84.

53. Utar Z, Majid MIA, Adenan MI, Jamil MFA, Lan TM. Mitragynine inhibits the COX-2 mRNA expression and prostaglandin $\mathrm{E}(2)$ production induced by lipopolysaccharide in RAW264.7 macrophage cells. J Ethnopharmacol. 2011;136(1):75-82.

54. Philipp AA, Wissenbach DK, Zoerntlein SW, Klein ON, Kanogsunthornrat J, Maurer HH. Studies on the metabolism of mitragynine, the main alkaloid of the herbal drug Kratom, in rat and human urine using liquid chromatography-linear ion trap mass spectrometry. J Mass Spectrom. 2009;44(8): 1249-61.

55. Philipp AA, Wissenbach DK, Weber AA, Zapp J, Maurer HH. Metabolism studies of the Kratom alkaloids mitraciliatine and isopaynantheine, diastereomers of the main alkaloids mitragynine and paynantheine, in rat and human urine using liquid chromatography-linear ion trap-mass spectrometry. J Chromatogr B Anal Technol Biomed Life Sci. 2011;879(15-16):1049-55.

56. Trakulsrichai S, Sathirakul K, Auparakkitanon S, Krongvorakul J, Sueajai J, Noumjad N, et al. Pharmacokinetics of mitragynine in man. Drug Des Devel Ther. 2015;9:2421-9.

57. Manda VK, Avula B, Ali Z, Khan IA, Walker LA, Khan SI. Evaluation of in vitro absorption, distribution, metabolism, and excretion (ADME) properties of mitragynine, 7-hydroxymitragynine, and mitraphylline. Planta Med. 2014;80(7):568-76.

58. Kruegel AC, Uprety R, Grinnell SG, Langreck C, Pekarskaya EA, Le Rouzic V, et al. 7-Hydroxymitragynine is an active metabolite of mitragynine and a key mediator of its analgesic effects. ACS Cent Sci. 2019;5(6):992-1001. https://doi.org/10.1021/ acscentsci.9b00141.
59. Kamble SH, Sharma A, King TI, Leon F, McCurdy CR, Avery BA. Metabolite profiling and identification of enzymes responsible for the metabolism of mitragynine, the major alkaloid of Mitragyna speciosa (kratom). Xenobiotica. 2019;49(11):1279-88.

60. Yusof SR, Mohd Uzid M, Teh E-H, Hanapi NA, Mohideen M, Mohamad Arshad AS, et al. Rate and extent of mitragynine and 7-hydroxymitragynine blood-brain barrier transport and their intra-brain distribution: the missing link in pharmacodynamic studies. Addict Biol. 2019;24(5):935-45.

61. Hemby SE, McIntosh S, Leon F, Cutler SJ, McCurdy CR. Abuse liability and therapeutic potential of the Mitragyna speciosa (kratom) alkaloids mitragynine and 7-hydroxymitragynine. Addict Biol. 2019;24(5): 874-85.

62. Yusoff NHM, Suhaimi FW, Vadivelu RK, Hassan Z, Rumler A, Rotter A, et al. Abuse potential and adverse cognitive effects of mitragynine (kratom). Addict Biol. 2016;21(1):98-110.

63. Hassan Z, Suhaimi FW, Ramanathan S, Ling K-H, Effendy MA, Muller CP, et al. Mitragynine (Kratom) impairs spatial learning and hippocampal synaptic transmission in rats. J Psychopharmacol. 2019;33(7):908-18.

64. Sabetghadam A, Navaratnam V, Mansor SM. Doseresponse relationship, acute toxicity, and therapeutic index between the alkaloid extract of $\mathrm{Mi}$ tragyna speciosa and its main active compound mitragynine in mice. Drug Dev Res. 2013;74(1): 23-30.

65. Ismail NIW, Jayabalan N, Mansor SM, Muller CP, Muzaimi M. Chronic mitragynine (kratom) enhances punishment resistance in natural reward seeking and impairs place learning in mice. Addict Biol. 2017;22(4):967-76.

66. Fakurazi S, Rahman SA, Hidayat MT, Ithnin $H$, Moklas MAM, Arulselvan P. The combination of mitragynine and morphine prevents the development of morphine tolerance in mice. Molecules. 2013;18(1):666-81.

67. Ilmie MU, Jaafar H, Mansor SM, Abdullah JM. Subchronic toxicity study of standardized methanolic extract of Mitragyna speciosa Korth in SpragueDawley Rats. Front Neurosci. 2015;9:189.

68. Kong WM, Chik Z, Ramachandra M, Subramaniam U, Aziddin RER, Mohamed Z. Evaluation of the effects of Mitragyna speciosa alkaloid extract on cytochrome P450 enzymes using a high throughput assay. Molecules. 2011;16(9):7344-56.

69. Meireles V, Rosado T, Barroso M, Soares S, Gonçalves J, Luís Â, et al. Mitragyna speciosa: clinical, 
toxicological aspects and analysis in biological and non-biological samples. Medicines. 2019;6(1):35.

70. Azizi J, Ismail S, Mordi MN, Ramanathan S, Said MIM, Mansor SM. In vitro and in vivo effects of three different Mitragyna speciosa korth leaf extracts on phase II drug metabolizing enzymes-glutathione transferases (GSTs). Molecules. 2010;15(1):432-41.

71. Anwar R, Hussin HA, Ismail S, Mansor MS. In vitro effect of mitragynine on activity of drug metabolizing enzymes, n-demethylase and glutathione s-transferase in streptozotocin-induced diabetic rats. Pharmacologyonline. 2012;1:68-75.

72. Azizi J, Ismail S, Mansor SM. Mitragyna speciosa Korth leaves extracts induced the CYP450 catalyzed aminopyrine- $N$-demethylase (APND) and UDP-glucuronosyl transferase (UGT) activities in male Sprague-Dawley rat livers. Drug Metabol Drug Interact. 2013;28(2):95-105.

73. Lim EL, Seah TC, Koe XF, Wahab HA, Adenan MI, Jamil MFA, et al. In vitro evaluation of cytochrome P450 induction and the inhibition potential of mitragynine, a stimulant alkaloid. Toxicol In Vitro. 2013;27(2):812-24.

74. Hughes RL. Fatal combination of mitragynine and quetiapine-a case report with discussion of a potential herb-drug interaction. Forensic Sci Med Pathol. 2019;15(1):110-3.

75. Chittrakarn S, Sawangjaroen K, Prasettho S, Janchawee B, Keawpradub N. Inhibitory effects of kratom leaf extract (Mitragyna speciosa Korth.) on the rat gastrointestinal tract. J Ethnopharmacol. 2008;116(1):173-8.

76. Reanmongkol W, Keawpradub N, Sawangjaroen K. Effects of the extracts from Mitragyna speciosa Korth. leaves on analgesic and behavioral activities in experimental animals. Songklanakarin J Sci Technol. 2007;29(Suppl 1):39-48.

77. Stolt A-C, Schroder H, Neurath H, Grecksch G, Hollt $\mathrm{V}$, Meyer MR, et al. Behavioral and neurochemical characterization of kratom (Mitragyna speciosa) extract. Psychopharmacology. 2014;231(1):13-25.

78. Singh D, Müller CP, Vicknasingam BK. Kratom (Mitragyna speciosa) dependence, withdrawal symptoms and craving in regular users. Drug Alcohol Depend. 2014;139:132-7.

79. Hassan Z, Muzaimi M, Navaratnam V, Yusoff NHM, Suhaimi FW, Vadivelu R, et al. From Kratom to mitragynine and its derivatives: physiological and behavioural effects related to use, abuse, and addiction. Neurosci Biobehav Rev. 2013;37(2): 138-51.
80. Muller CP, Schumann G. Drugs as instruments: a new framework for non-addictive psychoactive drug use. Behav Brain Sci. 2011;34(6):293-310.

81. Singh DP, Narayanan SP, Muller CPP, Vicknasingam BP, Yucel MP, Ho ETWP, et al. Long-term cognitive effects of kratom (Mitragyna speciosa Korth) use. J Psychoactive Drugs. 2019;51(1):19-27.

82. Singh D, Müller CP, Murugaiyah V, Hamid SBS, Vicknasingam BK, Avery B, et al. Evaluating the hematological and clinical-chemistry parameters of kratom (Mitragyna speciosa) users in Malaysia. J Ethnopharmacol. 2018;214:197-206.

83. Singh D, Narayanan S, Müller CP, Swogger TM, Rahim AA, Leong Bin Abdullah FI, et al. Severity of kratom (Mitragyna speciosa Korth) psychological withdrawal symptoms. J Psychoactive Drugs. 2018;50(5):445-50.

84. Singh D, Chye Y, Suo C, Yücel M, Grundmann O, Ahmad MZ, et al. Brain magnetic resonance imaging of regular kratom (Mitragyna speciosa Korth.) users: a preliminary study. Malays J Med Heal Sci. 2018;14(Sup 1):65-70.

85. Singh D, Abdullah MFIL, Vicknasingam BK, Müller $\mathrm{CP}$. Substance use disorder related to kratom (Mitragyna speciosa) use in Malaysia. Curr Psychopharmacol. 2019;8(1):64-71.

86. Swogger MT, Walsh Z. Kratom use and mental health: a systematic review. Drug Alcohol Depend. 2018;183:134-40.

87. Smith KE, Lawson T. Prevalence and motivations for kratom use in a sample of substance users enrolled in a residential treatment program. Drug Alcohol Depend. 2017;180:340-8.

88. Boyer EW, Babu KM, Adkins JE, McCurdy CR, Halpern JH. Self-treatment of opioid withdrawal using kratom (Mitragynia speciosa korth). Addiction. 2008;103(6):1048-50.

89. Hanna J. Bogus Kratom market exposed. Entheogen Rev. 2012;12(1):26-8.

90. Kikura-Hanajiri R, Kawamura M, Maruyama T, Kitajima M, Takayama H, Goda Y. Simultaneous analysis of mitragynine, 7-hydroxymitragynine, and other alkaloids in the psychotropic plant "kratom"(Mitragyna speciosa) by LC-ESI-MS. Forensic Toxicol. 2009;27(2):67-74.

91. Lydecker AG, Sharma A, McCurdy CR, Avery BA, Babu KM, Boyer EW. Suspected adulteration of commercial kratom products with 7-hydroxymitragynine. J Med Toxicol 2016/10/17. 2016;12(4): 341-9. 
92. Nacca N, Schult RF, Li L, Spink DC, Ginsberg G, Navarette K, et al. Kratom adulterated with phenylethylamine and associated intracerebral hemorrhage: linking toxicologists and public Health Officials to Identify Dangerous Adulterants. J Med Toxicol. 2019.

93. Arndt T, Claussen U, Güssregen B, Schröfel S, Stürzer B, Werle A, et al. Kratom alkaloids and $O$ desmethyltramadol in urine of a "Krypton" herbal mixture consumer. Forensic Sci Int. 2011;208(1-3): 47-52.

94. CDC. Salmonella outbreaks linked to kratom. 2018.

95. Dixon RB, Waggoner D, Davis M, Rembold K, Dasgupta A. Contamination of some kratom products with salmonella. Ann Clin Lab Sci. 2019;49(5): 675-7.

96. Kuehn B. Kratom-related deaths. JAMA. 2019;321(20):1966.

97. Eggleston W, Stoppacher R, Suen K, Marraffa JM, Nelson LS. Kratom use and toxicities in the United States. Pharmacotherapy. 2019;39(7):775-7.

98. Lu J, Wei H, Wu J, Jamil MFA, Tan ML, Adenan MI, et al. Evaluation of the cardiotoxicity of mitragynine and its analogues using human induced pluripotent stem cell-derived cardiomyocytes. PLoS One. 2014;9(12):e115648-e115648.

99. Abdullah HMA, Haq I, Lamfers R. Cardiac arrest in a young healthy male patient secondary to kratom ingestion: is this "legal high" substance more dangerous than initially thought? BMJ Case Rep. 2019;12(7):e229778. https://www.researchgate.net/ publication/334589099_Cardiac_arrest_in_a_young healthy_male_patient_secondary_to_kratom_inges tion_is_this_'legal_high'_substance_more_dangerous_ than_initially_thoug.

100. Sheleg SV, Collins GB. A coincidence of addiction to "Kratom" and severe primary hypothyroidism. J Addict Med. 2011;5(4):300-1.

101. Pathak V, Hahn C, Cabellon M, Aris R. Adult respiratory distress syndrome secondary to the use of herbal drug kratom. Am J Respir Crit Care Med. 2014;189:1.

102. Jaliawala HA, Abdo T, Carlile PV. Kratom; a potential cause of acute respiratory distress syndrome. Am J Respir Criti Care Med. 2018;197:A6604.

103. Murthy P, Clark D. An unusual cause for neonatal abstinence syndrome. Paediatr Child Health. $2019 ; 24: 12-4$.

104. Eldridge WB, Foster C, Wyble L. Neonatal abstinence syndrome due to maternal Kratom use.
Pediatrics. 2018;142(6):e20181839. https://doi.org/ 10.1542/peds.2018-1839.

105. Smid MC, Charles JE, Gordon AJ, Wright TE. Use of Kratom, an opioid-like traditional herb, in pregnancy. Obstet Gynecol. 2018;132(4):926-8.

106. Mackay L, Abrahams R. Novel case of maternal and neonatal kratom dependence and withdrawal. Can Fam Physician. 2018;64(2):121-2.

107. Davidson L, Rawat M, Stojanovski S, Chandrasekharan P. Natural drugs, not so natural effects: neonatal abstinence syndrome secondary to "kratom". J Neonatal Perinatal Med. 2019;12(1):109-12.

108. Waters M, Oxner A, Krajden S, Sultanian R. Acute liver injury associated with khat use in a 24-year-old male. Case Rep Hepatol. 2018;2018:2816907.

109. Dorman C, Wong M, Khan A. Cholestatic hepatitis from prolonged kratom use: a case report. Hepatology. 2015;61(3):1086-7.

110. Osborne CS, Overstreet AN, Rockey DC, Schreiner AD. Drug-induced liver injury caused by kratom use as an alternative pain treatment amid an ongoing opioid epidemic. J Investig Med high Impact Case Rep. 2019;7:2324709619826167.

111. Antony A, Lee T-P. Herb-induced liver injury with cholestasis and renal injury secondary to short-term use of Kratom (Mitragyna speciosa). Am J Ther. 2019;26(4):e546-7.

112. Riverso M, Chang M, Soldevila-Pico C, Lai J, Liu X. Histologic characterization of Kratom use-associated liver injury. Gastroenterol Res 2018/02/23. 2018;11(1):79-82.

113. Tayabali K, Bolzon C, Foster P, Patel J, Kalim MO. Kratom: a dangerous player in the opioid crisis. J Community Hosp Intern Med Perspect. 2018;8(3): 107-10.

114. Griffiths CL, Gandhi N, Olin JL. Possible kratominduced hepatomegaly: a case report. J Am Pharm Assoc (2003). 2018;58(5):561-3.

115. Drago JZ, Lane B, Kochav J, Chabner B. The Harm in Kratom. Oncologist. 2017;22(8):1010-1.

116. Fernandes CT, Iqbal U, Tighe SP, Ahmed A. Kratominduced cholestatic liver injury and its conservative management. J Investig Med High Impact Case Rep. 2019;7:2324709619836138.

117. Tatum WO, Hasan TF, Coonan EE, Smelick CP. Recurrent seizures from chronic kratom use, an atypical herbal opioid. Epilepsy Behav case Rep. 2018;10:18-20. 
118. Burke D, Shearer A, Van Cott A. Two cases of provoked seizure associated with Kratom Ingestion (P4. 5-030). Neurology. 2019;92(15 Supplement):4.5030.

119. Corkery JM, Streete P, Claridge H, Goodair C, Papanti D, Orsolini L, et al. Characteristics of deaths associated with kratom use. J Psychopharmacol. 2019;33(9):1102-23.

120. Gershman K, Timm K, Frank M, Lampi L, Melamed $\mathrm{J}$, Gerona R, et al. Deaths in colorado attributed to Kratom. N Engl J Med. 2019;380(1):97-8.

121. Overbeek DL, Abraham J, Munzer BW. Kratom (Mitragynine) ingestion requiring naloxone reversal. Clin Pract Cases Emerg Med. 2019;3(1):24-6. https://doi.org/10.5811/cpcem.2018.11.40588.

122. Diep J, Chin DT, Gupta S, Syed F, Xiong M, Cheng J. Kratom, an emerging drug of abuse: a case report of overdose and management of withdrawal. A\&A Pract. 2018;10(8):192-4.

123. Rech MA, Donahey E, Cappiello Dziedzic JM, Oh L, Greenhalgh E. New drugs of abuse. Pharmacotherapy. 2015;35(2):189-97.

124. Rosenbaum CD, Carreiro SP, Babu KM. Here today, gone tomorrow... and back again? A review of herbal marijuana alternatives (K2, Spice), synthetic cathinones (bath salts), kratom, Salvia divinorum, methoxetamine, and piperazines. J Med Toxicol. 2012;8(1):15-32.
125. Mousa MS, Sephien A, Gutierrez J, O'Leary C. $\mathrm{N}$-Acetylcysteine for acute hepatitis induced by Kratom Herbal Tea. Am J Ther. 2018;25(5):e550-1. https://doi.org/10.1097/MJT.0000000000000631.

126. Stanciu CN, Gnanasegaram SA, Ahmed S, Penders T. Kratom withdrawal: a systematic review with case series. J Psychoact Drugs. 2019;51(1):12-8.

127. Kucharik M, Gupta A, Averkiou P, Luck GR, Ross AS. Complicated postoperative course secondary to kratom withdrawal: a case report. J Surg Case Rep. 2019;2019(11):rjz309.

128. Khazaeli A, Jerry JM, Vazirian M. Treatment of Kratom Withdrawal and Addiction With Buprenorphine. J Addict Med. 2018;12(6):493-5.

129. Galbis-Reig D. A Case Report of Kratom Addiction and Withdrawal. WMJ. 2019;115(1):49-52.

130. Agapoff JR, Kilaru U. Outpatient buprenorphine induction and maintenance treatment for kratom dependence: a case study. J Subst Use. 2019;24(6): $575-7$.

131. Pantano F, Tittarelli R, Mannocchi G, Zaami S, Ricci S, Giorgetti R, et al. Hepatotoxicity Induced by "the 3Ks": Kava, Kratom and Khat. Int J Mol Sci. 2016;17(4):580. 